\title{
Empreendedorismo e Marketing: perspectivas de discentes do curso de Odontologia da Universidade de Vassouras
}

\author{
Entrepreneurship and Marketing: perspectives of students of the Dentistry course at the University \\ of Vassouras

\section{Catharina Freire Huthmacher ${ }^{1}$, Oswaldo Luiz Cecilio Barbosa ${ }^{2}$, Luiz Felipe Gilson de O. Rangel' Carla Cristina Neves Barbosa ${ }^{2}$}

Como citar esse artigo. HUTHMACHER, C. F; BARBOSA, O. L.C; RANGEL, L. F. G. O; BARBOSA, C. C. N. Cidadania e Deficiência. Mosaico -Revista Multidisciplinar de Humanidades, Vassouras, v. 12, n. 2, p. 08-13, mai./ago. 2021.

Nota da Editora. Os artigos publicados na Revista Mosaico são de responsabilidade de seus autores. As informações neles contidas, bem como as opiniões emitidas, não representam pontos de vista da Universidade de Vassouras ou de suas Revistas.

\begin{abstract}
Resumo
A Odontologia, assim como diversas outras áreas da saúde, vem evoluindo consideravelmente não só no que diz respeito às técnicas, mas também na forma de enxergar o novo modelo de mercado de trabalho cada vez mais concorrido. $\mathrm{O}$ empreendedorismo tem forte impacto social juntamente aos conhecimentos sobre marketing que auxiliam no destaque desses profissionais. Este estudo teve como objetivo verificar a diferença do perfil empreendedor e conhecimentos de marketing dos discentes do Curso de Graduação em Odontologia da Universidade de Vassouras, entre as turmas de terceiro período, quinto período e sétimo período, por meio de uma pesquisa descritiva do tipo transversal. Os dados foram coletados a partir de um formulário do Google Forms, contendo questionário para avaliação do perfil empreendedor e outro questionário a respeito de conhecimento de estratégias de marketing e sua importância para a vida profissional. Esses dados foram tabulados e submetidos à análise estatística descritiva. Participaram do estudo 64 estudantes dos três períodos. Em relação ao perfil empreendedor, os alunos de ambos os períodos foram classificados por "muitas características empreendedoras" de acordo com a pesquisa. Sobre conhecimentos de marketing, os alunos afirmaram conhecer e acreditar na importância do marketing na vida profissional. Com isso, mostrou-se o quão apto estes discentes dos períodos citados estão para engajar no mercado de trabalho.

Palavras-chave: Odontologia, Marketing, Empreendedorismo.
\end{abstract}

\begin{abstract}
Dentistry, as well as several other areas of health, has evolved considerably not only in terms of techniques, but also in terms of seeing the new model of the increasingly competitive labor market. Entrepreneurship has a strong social impact together with knowledge about marketing that helps to highlight these professionals. This study aimed to verify the difference in the entrepreneurial profile and marketing knowledge of the students of the Undergraduate Dentistry Course at the University of Vassouras, between the third, fifth and seventh period classes, through a descriptive cross-sectional research. The data were collected from a Google Forms form, containing a questionnaire to assess the entrepreneurial profile and another questionnaire about knowledge of marketing strategies and their importance for professional life. These data were tabulated and submitted to descriptive statistical analysis. 64 students from the three periods participated in the study. Regarding the entrepreneurial profile, students from both periods were classified by "many entrepreneurial characteristics" according to the survey. Regarding marketing knowledge, students said they knew and believed in the importance of marketing in their professional lives. With that, it was shown how apt these students from the periods mentioned are to engage in the job market.

Keywords: Dentistry, Marketing, Entrepreneurship.
\end{abstract}

\section{Introdução}

A Odontologia, assim como diversas outras áreas da saúde, vem evoluindo consideravelmente não só no que diz respeito às técnicas, equipamentos, mas também na forma de enxergar o novo modelo de mercado de trabalho cada vez mais concorrido. O Brasil é o país com a maior concentração de dentistas por habitante no mundo. Em 2018 no Brasil, eram 310.401 cirurgiõesdentistas registrados nos conselhos. Agora em 2020, de acordo com o Conselho Federal de Odontologia, são 339.550 dentistas registrados, um aumento de 29.149 profissionais em apenas 2 anos (CFO, 2020). Esse fato está diretamente associado ao número de instituições de ensino existentes, que contava com o número de 220 cursos entre públicas e privadas, até o primeiro semestre do ano de 2018. (SAN MARTIN et al., 2018).

Ao concluir a graduação em Odontologia, três caminhos prováveis podem ser seguidos: a área acadêmica, profissional contratado ou servidor público e profissional autônomo com responsabilidade de gestão do próprio consultório ou clínica (BAUR et al., 2016).

A quantidade de profissionais formados todos os anos e as mudanças no mercado de trabalho acabam fazendo com que somente as habilidades técnicas não se

Afiliação dos autores

${ }^{1}$ Discente do curso de Odontologia da Universidade de Vassouras.

${ }^{2}$ Docente do curso de Odontologia da Universidade de Vassouras.

* Email de correspondência: freire.catharina@yahoo.com.br 
destaquem, ou seja, não é mais um fator determinante para o sucesso da carreira no que diz respeito a atendimentos clínicos, sendo necessários outros conceitos para fazer esta diferenciação no mercado, tais como, noções de empreendedorismo, gestão, administração, economia e marketing, obedecendo a normas éticas e legais da profissão (GARBIN et al., 2010).

Infelizmente, estes conhecimentos e habilidades não surgem de maneira espontânea no profissional. Há um papel muito importante na participação das universidades em formações mais abrangentes para os alunos de Odontologia (ROCHA e FREITAS, 2014). Segundo Silva (2016), o empreendedorismo tem forte impacto social, pois as pequenas e micro empresas são responsáveis por $70 \%$ dos empregos gerados no Brasil. $\mathrm{O}$ empreendedorismo está fortemente associado ao perfil do indivíduo, pois ele é o agente principal para as decisões que serão tomadas, destaca-se nesse contexto a auto eficácia nos empreendedores, que é uma crença individual nele mesmo de alcançar seu objetivo com sucesso (SANTOS, CAETANO e CURRAL, 2010).

O Marketing em Odontologia contribui como ferramenta inovadora e segmentada para abordagem e captação de clientes/pacientes e consequentemente o sucesso pessoal e profissional do cirurgião-dentista. Para isso, é necessário o conhecimento das ferramentas de marketing para uma adequada comunicação entre o profissional e cliente, facilitando assim o alcance dos objetivos e metas do cirurgião-dentista. (ARCIER et al., 2008).

Dentre algumas ferramentas que facilitam a captação de clientes/pacientes, economizando tempo e recursos, existe a $5 \mathrm{~W} 2 \mathrm{H}(5 \mathrm{~W}$ : What [o que será feito?] - Why [por que será feito?] - Where [onde será feito?] When [quando?] - Who [por quem será feito?] 2H: How [como será feito?] - How much [quanto vai custar). (ENDEAVOR, 2017).

O conhecimento em novas tecnologias favorece a comunicação intelectual e novas formas de saber da sociedade atual, cuja característica principalé a facilidade e rapidez de acesso às informações (SANTAELLA, 2001).

As comunicações constituem um importantíssimo setor industrial, juntamente a uma experiência individual diária, um terreno de confronto político, um sistema de intervenção cultural e de agregação social, uma maneira de se informar, de entreter-se e de passar o tempo (WOLF, 1999).

Segundo Santaella (2001), as novas tecnologias começaram a descentralizar a comunicação, afetando a recepção de massa ao permitir ao usuário maior controle sobre o processo de comunicação. Com isso, torna-se cada vez mais necessário o conhecimento e aplicação do marketing na abordagem do consumidor que está cercado de novas informações com temas de seu interesse o tempo inteiro, sempre ao alcance dele, sem muito esforço, na palma da sua mão através dos smartphones.

Devido à importância das habilidades empreendedoras para a formação complementar dos profissionais da saúde em geral e especificamente neste caso os cirurgiões-dentistas, este estudo teve como objetivo identificar o perfil empreendedor e conhecimentos de marketing e suas possíveis variações de acordo com o nível de aprendizado (períodos estudados) entre estudantes do Curso de Graduação em Odontologia da Universidade de Vassouras.

\section{Materiais e métodos}

O presente estudo foi realizado após sua plena aprovação pelo Comitê de Ética da Universidade de Vassouras, com parecer sob o número 29910320.0.0000.5290. Classifica-se como uma pesquisa descritiva do tipo transversal. Sua população foi composta por alunos do terceiro, quinto e sétimo períodos da Universidade de Vassouras.

Os dados foram coletados a partir de formulário do Google Forms que foi enviado com o Termo de Consentimento Livre e Esclarecido (TCLE) e o questionário. A pesquisa foi dividida em dois questionários, comportamento empreendedor adaptado que avalia a análise do desempenho e outro sobre a importância das noções de marketing.

$\mathrm{O}$ quadro que avalia o perfil do empreendedor possui umaescala onde de 120 a 150 pontos (possuimuitas características empreendedoras): você provavelmente é um empreendedor, possui as características comuns aos empreendedores e tem tudo para se diferenciar em sua organização; de 90 a 119 pontos, você possui muitas características empreendedoras e às vezes se comporta como um, porém pode melhorar ainda mais se equilibrar os pontos ainda fracos com os pontos fortes; de 60 a 89 pontos, você ainda não é muito empreendedor e provavelmente se comporta, na maior parte do tempo, como um administrador tradicional e não um "fazedor", para se diferenciar e começar a praticar atitudes empreendedoras, procure analisar os seus principais pontos fracos e definir estratégias pessoais para eliminálos; e menos de 59 pontos, você não é empreendedor e, se continuar a agir como age dificilmente será, isso não significa que você não tenha qualidades, apenas que prefere seguir a ser seguido, se sua posição na empresa exigir um perfil mais empreendedor, reavalie sua carreira e seus objetivos pessoais (Quadro 1) (DORNELAS, 2003 apud UNITECNE, 2004).

Em relação ao marketing, o questionário possuía opções de resposta múltipla escolha como sim ou não (Tabela 1).

Os dados foram transcritos e tabulados em planilha Excel ${ }^{\circledR}$ e então submetidos a uma análise 


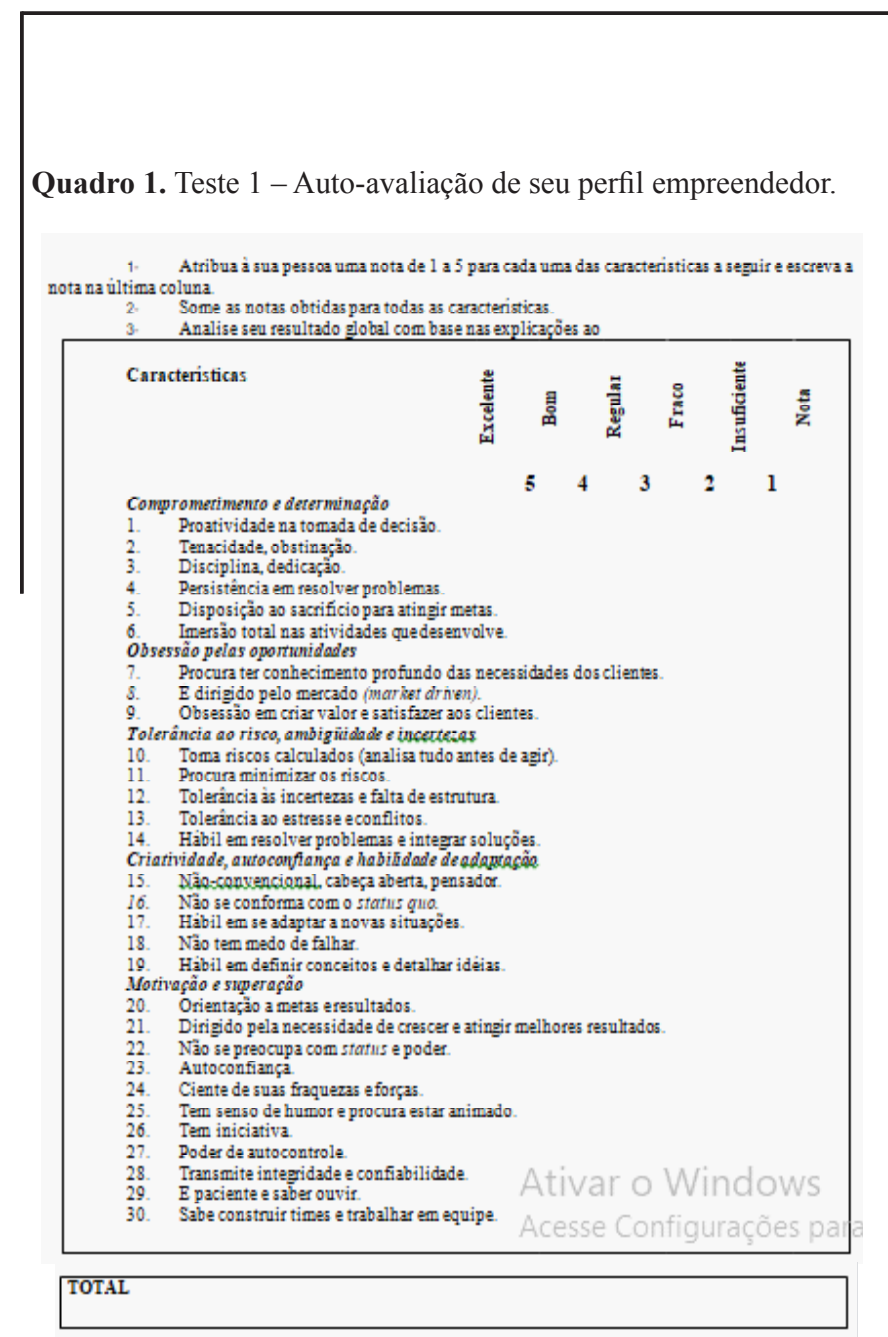

Fonte: DORNELAS (2004)

Tabela 1. Avaliação da importância do Marketing para o profissional de Odontologia.

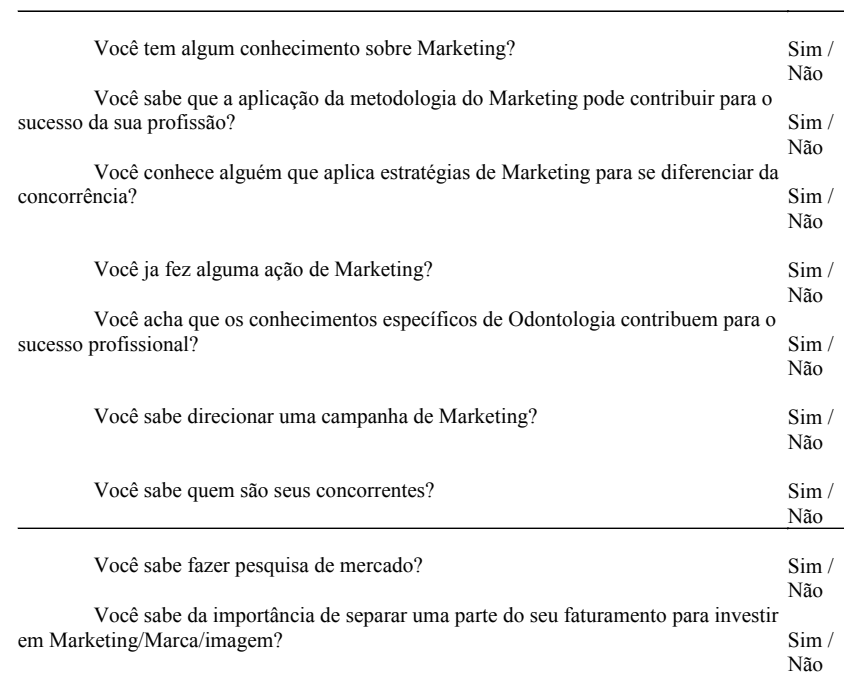

Fonte: BLOG ROCKCONTENT. Pesquisa de mercado. estatística descritiva, quantitativa comparando a visão de cada período.

\section{Resultados}

Concordaram em realizar o estudo 64 estudantes matriculados nas turmas de Odontologia da Universidade de Vassouras, sendo 19 do terceiro, 19 do quinto e 26 do sétimo períodos (Figura 1).

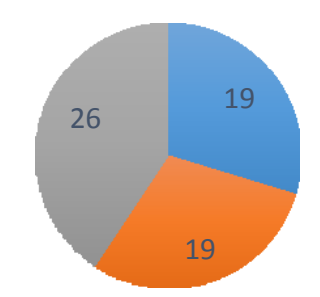

- Terceiro Período Quinto Período Sétimo Período

Figura 1. Representação do número de participantes da pesquisa.

Em relação ao Perfil Empreendedor, foi feito o somatório dos resultados individuais e dividido pelo número de questionários realizados em cada turma. Ambos os períodos se enquadraram dentro da classificação média de 90 a 119 pontos qualificandoas da seguinte maneira: "muitas características empreendedoras" (Figura 2).

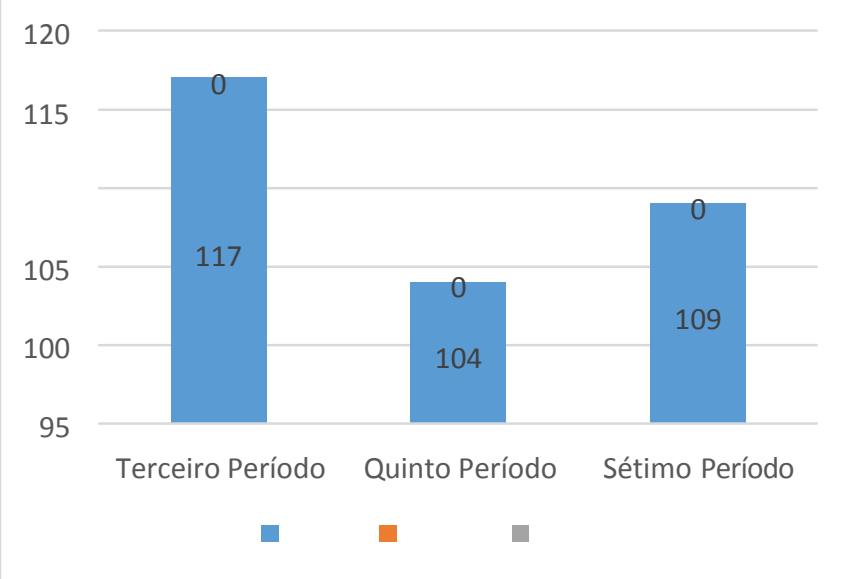

Figura 2. Representação da pontuação média por turma em relação ao perfil empreendedor.

Quando avaliado separadamente, no terceiro período apenas 1 aluno (5\%) obteve menos de 89 pontos, que o qualifica como um perfil fraco de empreendedor, 4 alunos $(21 \%)$ apresentaram um perfil com mais de 120 pontos, se caracterizando como um perfil empreendedor. A amostra do quinto período não apresentou perfil empreendedor baixo, tendo 16 alunos (84\%) com perfil 
médio e 3 alunos (16\%) tiveram um perfil alto. No sétimo observou que a metade da amostra possuía perfil médio e a outra metade perfil alto.

A respeito do conhecimento em Marketing, 8 alunos $(42 \%)$ do terceiro período disseram que sim, enquanto nos quinto e sétimo períodos 11 alunos (52\%) e 11 alunos (42\%), respectivamente. Em relação a credibilidade sobre o marketing para ajudar no sucesso profissional, 14 alunos (74\%) do terceiro, 15 alunos $(69 \%)$ do quinto e 19 alunos (73\%) do sétimo período acreditam nesta ferramenta (Figura 3).

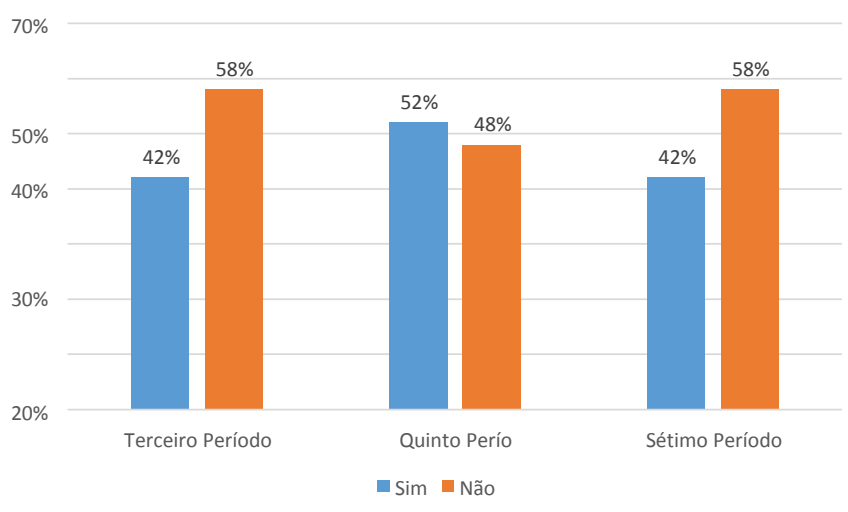

Figura 3. Avaliação por período sobre possuírem conhecimentos de marketing.

Quando questionados se já havíam criado alguma campanha de Marketing ambas as turmas tiveram um resultado semelhante estatisticamente, 16 alunos $(84 \%)$ disseram que não no terceiro e quinto períodos e 22 alunos (85\%) no sétimo. Na sequência se saberiam direcionar uma campanha de marketing, apenas 1 aluno (5\%) do terceiro período se considera apto, enquanto 2 alunos $(10 \%)$ e 3 alunos (12\%) do quinto e sétimo períodos respectivamente.

Em relação ao conhecimento de quem seriam seus potenciais concorrentes, 12 alunos $(63 \%)$ do terceiro período, 13 alunos (68\%) do quinto e 15 alunos (58\%) do sétimo período acreditam que conhecem (Figura 4).

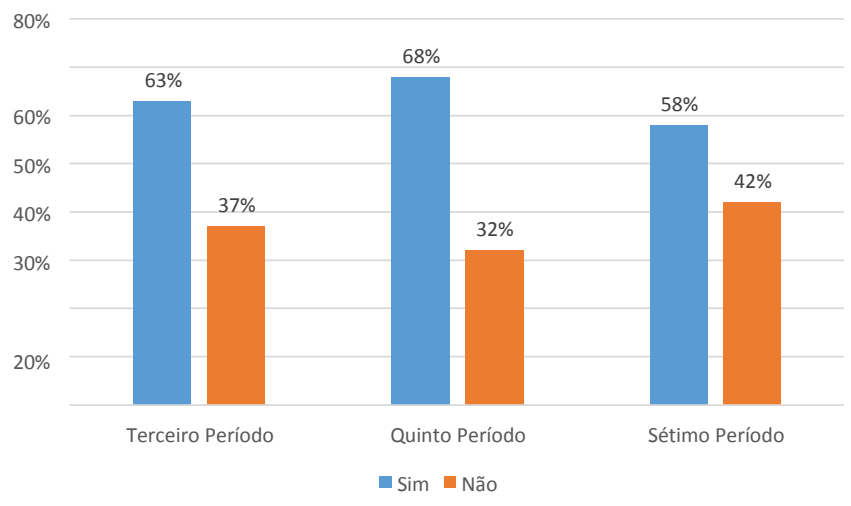

Figura 4. Representação das turmas a respeito de conhecerem seus concorrentes.
Considerando se saberia realizar uma pesquisa de mercado, 17 alunos $(90 \%)$ do terceiro período, 13 alunos $(68 \%)$ do quinto e 22 alunos $(85 \%)$ do sétimo responderam negativamente ao questionamento.

No tópico sobre a importância de separar um percentual do faturamento para investir em marketing, imagem e marca, 14 alunos (74\%) do terceiro período, 6 alunos (32\%) do quinto e 10 alunos (38\%) do sétimo, acham que é importante (Figura 5).

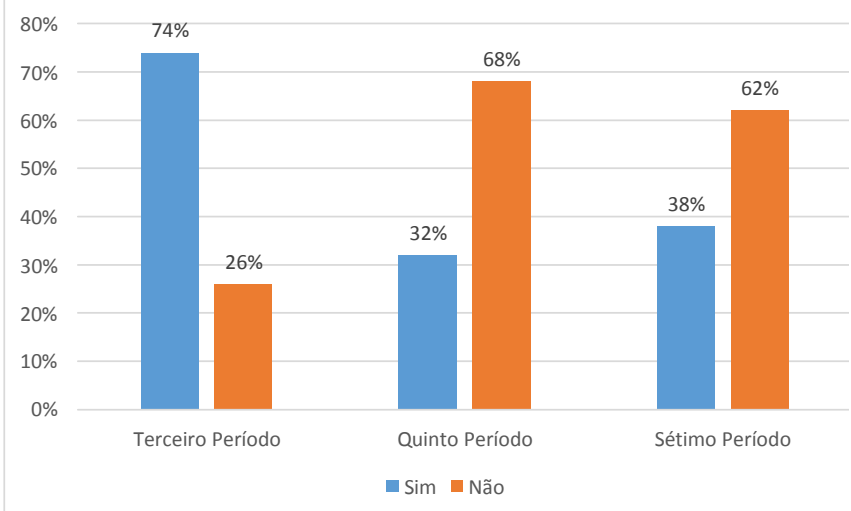

Figura 5. Representação do número de participantes que sabem da importância de separar uma parte de seu faturamento para investir em marketing.

\section{Discussão}

Os resultados demonstram que quando se comparam isoladamente os alunos das turmas entre si, os perfis empreendedores estão em constante evolução, melhorando conforme vão se passando os períodos. Talvez isso ocorra devido à responsabilidade, dos estudantes do $7^{\circ}$ período, por estarem próximo de se formarem, interferindo diretamente nos seus comportamentos.

Segundo Krüger e Minello (2018) o comportamento e perfil empreendedor devem ser estimulados ainda na graduação, tendo em vista que podem realmente fazer a diferença no mercado de trabalho.

Ser somente um cirurgião-dentista com especializações não garante sucesso profissional em sua clínica, como relatado anteriormente, o mercado está saturado, ou seja, atitudes e comportamentos podem ser o diferencial (ARCIER et al., 2008).

Ao contrário do que acham, ser empreendedor não se restringe somente em habilidades de administração e ser dono de um estabelecimento, envolve muito mais que isso, como por exemplo, habilidades de liderança, iniciativa, planejamento estratégico e muito mais (SEBRAE, 2020).

Deve-se observar que como o perfil empreendedor (DORNELAS, 2003 apud UNITECNE, 2004) do curso se classifica como médio, segundo o questionário utilizado, 
ainda há muito que se fazer. Na prática, sabe-se que ser mediano não é mais suficiente. A Universidade tem um papel fundamental pela frente, e deve se preocupar com capacitação de seus professores para uma visão mais moderna do mercado de trabalho, preparando ainda mais seus estudantes para a vida profissional (MINUZZI; VARGAS e FIALHO, 2016).

Os resultados obtidos acima demonstram que há uma necessidade a ser preenchida no que diz respeito à qualificação básica em marketing. Por mais que não tenha uma disciplina exclusiva para esse assunto de forma obrigatória pelas Diretrizes curriculares nacionais do curso de odontologia, seria interessante a implementação, pois certamente aumentariam a possibilidade dos estudantes saírem um passo à frente no mercado de trabalho em relação aos conhecimentos e recursos que o marketing podem proporcionar na alavancagem da carreira profissional (MOTA, 2011).

De acordo com Lacerda (2005), os concorrentes são considerados aqueles que ofertam um mesmo produto ou serviço para o mesmo público alvo, porém, atualmente este conceito tem se modificado um pouco. Vivencia-se uma nova era, onde as pessoas estão passando a observar com mais detalhes a qualidade de um serviço prestado, a atenção recebida durante o atendimento, o cuidado, dentre outras características. Também estão optando em quais serviços ou produtos vão destinar o seu dinheiro. Isso nos traz uma reflexão, que talvez não só as empresas do mesmo segmento sejam concorrentes, mas todas as demais. Deve-se então buscar despertar nos clientes/pacientes a necessidade de se optar pelos tratamentos odontológicos na lista de prioridades (MORAES, 2016).

Há uma diferença significativa entre a percepção do terceiro período em comparação com o quinto e sétimo períodos quando questionados sobre a importância de separar e investir uma parte do faturamento. Enquanto no terceiro período $74 \%$ acham isso importante, no quinto e sétimo períodos essa classificação de importância cai para $32 \%$ e $38 \%$ respectivamente. Esses dados demonstram uma situação preocupante para o sétimo período, pois como estão prestes de se introduzirem ao mercado de trabalho, pode ser que demore a enxergar que aplicar recursos em marketing é de extrema importância nos dias atuais, ainda mais se considerar o aumento de profissionais que se formam anualmente, saturando o mercado de trabalho (SAN MARTIN et al., 2018). Os principais objetivos do Marketing são a melhora do resultado financeiro, melhora da qualidade de vida e consequentemente, o prestígio social por meio de um excelente atendimento ao paciente (KOTLER, 2000).

É muito importante conhecer as dores e anseios dos clientes/pacientes para que se possa saber comunicar da melhor forma possível com eles, aumentando assim a chance de converter uma avaliação clínica em fechamento de venda do tratamento, com estratégias e ferramentas que o marketing pode ensinar. Esse processo se torna muito mais fácil e eficaz. Faz-se então necessária a inclusão destes conceitos nas grades curriculares das universidades (NORONHA, 2014).

\section{Conclusão}

De acordo com os dados coletados, esta pesquisa mostrou o quão apto os alunos dos períodos citados estão para embarcar no mercado de trabalho. Possuem conhecimentos de marketing, o que os faz se diferenciar e se destacar dos que não possuem e estão no mercado de trabalho. Além de conhecerem, sabem e acreditam na importância do marketing para o sucesso profissional.

O ponto fraco dos alunos foi o conhecimento sobre pesquisa de mercado e o direcionamento das campanhas de marketing. Como apresentado acima, esse conhecimento tem um papel muito importante para aquisição de novos pacientes/clientes e destaque dos profissionais entre a ampla concorrência.

Considera-se que as universidades deveriam dar a opção deste tipo de informação na grade curricular dos cursos de Odontologia, melhorando assim o preparo dos alunos no mercado e aumentando a visão de concorrência e estratégias para se destacarem e serem excelentes profissionais e empreendedores.

\section{Referências}

ARCIER, Natália Mendes et al. A importância do marketing odontológico para enfrentar um mercado competitivo. Revista Odontológica de Araçatuba, v. 29, n. 1, p. 13-19, Janeiro/Junho, 2008.

BAUR, Gustavo et al. Perfil empreendedor dos estudantes de Odontologia da Universidade Federal de Santa Catarina. Revista da ABENO, v. 16, n. 2, p. 77-82, 2016

CONSELHO FEDERAL DE ODONTOLOGIA. 2020. Disponível em: http://cfo.org.br/website/estatisticas/quantidade-geral-de-entidades-eprofissionais- ativos/. Acesso: 27 fev. 2020

DORNELAS, José Assis. Empreendedorismo Corporativo: Como ser empreendedor, inovar e se diferenciar em organizações estabelecidas. Rio de Janeiro, Campus, 2003. In: Material da Escola de Empreendedores da Unitecne - 2004

ENDEAVOR. 5W2H: é hora de tirar as dúvidas e colocar a produtividade no seu dia a dia. Disponível em: https://endeavor.org.br/pessoas/5w $2 \mathrm{~h} /$. Publicado em: 08 de fevereiro, 2017. Atualizado em: 17 jun 2020.

GARBIN, Artênio José Isper et al. Publicidade em Odontologia: Avaliação dos Aspectos Éticos Envolvidos. RGO, v. 58, n.1, p. 85-89, jan./mar. 2010.

KOTLER, Philip. Administração de Marketing. $10^{\mathrm{a}}$ ed., $7^{\mathrm{a}}$ reimpressão. Tradução Bazán Tecnologia e Lingüística; revisão técnica Arão Sapiro. São Paulo: Prentice Hall, 2000.

KRÜGER, Cristiane, MINELLO, Italo. As características comportamentais empreendedoras dos estudantes de graduação. Universidade do Vale do Itajaí. Revista Alcance, v.25, n.2, 2018.

LACERDA, Idelma. Qualidade no atendimento ao cliente como fator de crescimento empresarial. Monografia. 2005. Disponível em:

https://monografias.brasilescola.uol.com.br/administracao-financas/qualidade-no- atendimento-ao-cliente-como-fator-crescimento-empresarial. htm. Acesso: 30 Jul. 2020. 
MINUZZI, Cristiele Dal Osto; VARGAS, Katiuscia Schiemer; FIALHO, Camila Borges. Características comportamentais empreendedoras: em cena os futuros administradores. Revista de Empreendedorismo e Gestão de Pequenas Empresas. São Paulo, SP, Brasil, v. 5, n. 1, 2016.

MORAES, Roberta. 10 principais hábitos de consumo do brasileiro impactadospelacrise.2016.Disponívelem:https://www.mundodomarketing. com.br/reportagens/pesquisa/36852/10-principais- habitos-de-consumo-dobrasileiro-impactados-pela-crise.html. Acesso: 01 ago 2020.

MOTA, Hermano. Pesquisa de marketing: o que é e como aplicar. 2011. Disponível em: https://hermanomota.com.br/pesquisa-de-marketing-o-quee-e-como-aplicar/.

Acesso: 10 maio 2020.

NORONHA, José. Como entender melhor as necessidades e desejos dos clientes?, 2014. Disponível em: https://administradores.com.br/artigos/ como-entender-melhor-as- necessidades-e-desejos-dos-clientes. Acesso: 10 maio 2020.

ROCHA, Estevão Lima de Carvalho; FREITAS, Ana Augusta Ferreira. Avaliação do Ensino de Empreendedorismo entre Estudantes Universitários por meio do Perfil Empreendedor. RAC. Rio de Janeiro, v. 18, n. 4, art. 5, p. 465-486, Jul./Ago. 2014.

SAN MARTIN, Alissa Schmidt et al. Distribuição dos cursos de Odontologia e de cirurgiõesdentistas no Brasil: uma visão do mercado de trabalho. Revista da ABENO, v. 18, n.1, p. 63-73, 2018.

SANTAELLA, Lucia. Novos Desafios da Comunicação. Lumina-Facom/ UFJF, v.4, n.1, p.1- 10, jan/jun 2001.

SANTOS, Susana Correia; CAETANO, Antonio; CURRAL, Luis. Atitude dos Estudantes Universitários Face ao Empreendedorismo - Como Identificar o Potencial Empreendedor. Revista Portuguesa e Brasileira de Gestão. Out/Dez, 2010.

SEBRAE. Conheça características importantes para o comportamento empreendedor. Disponível em:

https://www.sebrae.com.br/sites/PortalSebrae/artigos/artigoshome/conhecacaracteristicas-importantes-para-o-comportamento- empreendedor, $638 \mathrm{~b} 5 \mathrm{~d} 2$ 7e8fdd410VgnVCM1000003b74010aRCRD. Acesso: 10 maio 2020.

SILVA, Flávio Augusto da. Geração de Valor. v. 3. São Paulo: Buzz Editora, 2016.

WOLF, Mauro. Teorias da comunicação. Lisboa: Presença, 1999. 